\title{
STRATEGI PENGEMBANGAN BISNIS CARGO PT. GARUDA INDONESIA, TBK DENGAN PENDEKATAN BUSINESS MODEL CANVAS
}

\author{
DEVELOPMENT STRATEGY OF CARGO BUSINESS PT. GARUDA INDONESIA, TBK \\ WITH BUSINESS MODEL CANVAS APPROACH
}

\author{
Ahmad Fariz Viali"), Amzul Rifin**), dan Imam Teguh Saptono*) \\ *) Sekolah Bisnis, Institut Pertanian Bogor \\ Jl. Raya Pajajaran, Bogor 16151 \\ ${ }^{* *}$ Departemen Agribisnis, Fakultas Ekonomi dan Manajemen, Institut Pertanian Bogor \\ Jl. Agatis Kampus IPB Darmaga, Bogor 16880
}

\begin{abstract}
The e-commerce market currently have sales 2016 expected to reach 4,4 billion USD will certainly affect the growth of freight forwarding, better known as cargo. The purpose of this research is to analyze the condition of Cargo Directorate by using business model canvas and make New Business Model Canvas Directorate of Cargo PT. Garuda Indonesia, Tbk. Instrument the analysis used in this research was Business Model Canvas (BMC), Importance and Performance Analysis (IPA), and Five Forces Porter Analysis. The result of initial identification of 9 block elements of BMC Directorate of Cargo as well as analysis of importance and performance level, there are 3 elements of priority blocks that need improvement namely customer segment, channel and revenue streams. Five forces porter analysis and Industry foresight in the Cargo industry became input on the improvement of 3 block elements. The change of customer segment elements is the target market becomes wider than customer port to port becomes customer door to door. Changes to channel elements are developed by expanding the opening of new channels such as outlets, sales outlets, booths, small counters. Development in revenue stream is the additional revenue from door to door, fee based income and revenue sharing from $B U M N$ synergy. Changes in all three elements also made changes in other elements, thus creating a new business model canvas that is beneficial for corporate development and appropriate industrial development.
\end{abstract}

Keywords: Cargo, BMC, IPA, five forces porter

\begin{abstract}
Abstrak: Berkembangnya pasar e-commerce saat ini mempunyai nilai penjualan 2016 yang diperkirakan telah mencapai 4,4 miliar USD tentunya akan berdampak pada pertumbuhan pengiriman barang atau yang lebih dikenal dengan nama cargo. Tujuan dari penelitian ini antara lain menganalisis kondisi Direktorat Cargo dengan menggunakan Business Model Canvas (BMC) dan membuat New BMC Direktorat Cargo PT. Garuda Indonesia, Tbk. Alat analisis yang digunakan dalam penelitian ini adalah BMC, Importance and Performance Analysis (IPA), dan Five Forces Porter. Hasil dari identifkasi awal dari 9 elemen blok BMC Direktorat Cargo disertai analisis tingkat kepentingan dan kinerja terdapat tiga elemen blok prioritas yang perlu dilakukan perbaikan, yaitu customer segment, channel, dan revenue streams. Five forces porter analysis dan Industry foresight pada industri Cargo menjadi masukan pada perbaikan 3 elemen blok. Perubahan elemen customer segmen, yaitu target pasar menjadi lebih luas dari customer port to port menjadi customer door to door. Perubahan pada elemen channel, yaitu pengembangan dengan memperbanyak pembukaan channel baru seperti gerai, sales outlet, booth, small counter. Pengembangan pada revenue stream, yaitu adanya pendapatan tambahan dari door to door, fee based income dan revenue sharing dari sinergi BUMN. Selain itu perubahan pada ketiga elemen tersebut juga menyebabkan pengembangan pada elemen Value Preposition, Customer Relationship, Key Patners, Key Activities serta pada elemen Key Resource dan Cost Structure agar dapat dioptimalkan dan efisiensi sehingga menciptakan new BMC yang bermanfaat bagi pengembangan perusahaan yang sesuai perkembangan industri.
\end{abstract}

Kata kunci: Cargo, BMC, IPA, five forces porter

${ }^{1}$ Alamat Korespondensi:

Email: farizviali@gmail.com 


\section{PENDAHULUAN}

Perekonomian Indonesia sebagai negara berkembang mengalami fluktuasi disetiap tahunnya dimana angka pertumbuhan ekonomi menjadi salah satu tolak ukur kemampuan suatu Negara. Dalam mencapai pertumbuhan ekonomi diperlukannya pengkajian potensi suatu daerah yang memberikan kontribusi dalam peningkatan perekonomian nasional. Hal ini tidak telepas dari keadaan demografi Indonesia yang terdiri dari kepulauan sehingga dapat memengaruhi perbedaan ekonomi suatu daerah dengan daerah lain. Ketidakmerataan ekonomi daerah membuat penyelarasan pembangunan ekonomi memerlukan perhatian khususnya daerah non-industri. Pada daerah tersebut membutuhkan moda transportasi barang baik darat dan udara untuk memenuhi kebutuhan daerah tersebut.

Moda transportasi barang atau yang sering disebut transportasi logistik memberikan peran dalam meningkatkan perekonomian, dapat dilihat pada Table 1 yang menjelaskan bahwa tranportasi darat menjadi alat angkut tertinggi dalam penyaluran barang. Meningingat secara demografi Indonesia sebagai Negara kepulauan, maka diperlukannya moda transportasi lain yang memberikan layanan yang cepat dalam menyalurkan barang seperti transportasi udara dan laut. Dimana kondisi logistik jalur udara masih belum optimal dan terdapat banyak potensi yang dapat di kembangkan.

Pada Tabel 1 mendeskripsikan bahwa share pengangkutan barang melalui transportasi udara masih sangat minim sekali dibawah $1 \%$. Kondisi inilah yang membuat pulau Jawa, Sumatra, Sulawesi, dan Bali lebih didominasi oleh moda jalan darat. Dibandingkan daerah timur seperti Maluku-Papua yang didominasi pengangkutan menggunakan transportasi laut dan udara. Laut dan angkasa adalah prasarana perangkutan yang harus dipandang sebagai pemersatu pulau-pulau menjadi kesatuan wilayah negara, bukan lagi sebagai pemisah antara satu pulau dengan pulau lainnya
(Setiani, 2015). Pengangkutan barang via udara memang lebih dominan di wilayah Indonesia timur hal ini juga disebabkan oleh jangkauan luas dan waktu lebih untuk mencapainya.

Meskipun begitu pengangkutan menggunakan transportasi udara tetap berkembang dikarenakan memiliki karakteristik yang kuat, yaitu kecepatan waktu dalam pengiriman. Saat ini penyediaan jasa pengakutan barang melalui udara sudah cukup berkembang di Indonesia. Hal ini tidak telepas dari peningkatan pengiriman barang pada setiap waktunya, salah satu pengguna jasa ini adalah layanan jual beli online atau yang lebih dikenal dengan e-commerce. Dimana tujuan dari e-commerce memberikan kemudahan dan kecepatan dalam pengiriman barang hingga keseluruh daerah. Perubahan perilaku ini merupakan peluang bagus bagi bisnis penerbangan (Ropi et al. 2016). Berkembangnya pasar e-commerce dengan nilai penjualan 2016 diperkirakan mencapai 4,4 miliar USD ini tentunya akan berdampak pada pertumbuhan pengiriman barang atau yang disebut cargo. Saat ini sudah banyak jasa pengiriman cargo yang melayani pengiriman dalam waktu cepat. Jenis pengiriman barang baik retail dan bahkan hingga pengiriman untuk skala pabrik (non-retail). Peluang bisnis yang berpotensi besar ini juga tidak dilewatkan oleh perusahaan jasa pengirman cargo salah satunya PT. Garuda Indonesia, Tbk melalui unit bisnis Cargo. Sebagai BUMN bidang airlines pengangkut penumpang dan barang, bisnis Cargo sangat berpotensi untuk dapat dikembangkan. Hal ini juga dapat dilihat pada perkembangan pendapatan Cargo PT. Garuda Indonesia, Tbk.

PT. Garuda Indonesia, Tbk sebagai BUMN yang memiliki tujuan untuk meraih keuntungan, telah menetapkan bahwa bisnis Cargo adalah salah satu dari empat revenue generator. Namun, kondisi saat ini belum signifikan jika dilihat dari data kontribusi Cargo terhadap pendapatan PT. Garuda Indonesia, Tbk secara keseluruhan pendapatan perusahaan.

Tabel 1. Data share pengangkutan barang berdasarkan pulau-pulau 2013

\begin{tabular}{lccccccc}
\hline Moda Transportasi & Sumatera & Jawa & Kalimantan & Sulawesi & Bali NTT & Maluku-Papua & Rata-rata \\
\hline Udara & $0,0 \%$ & $0,0 \%$ & $0,0 \%$ & $0,0 \%$ & $0,0 \%$ & $1,1 \%$ & $0,2 \%$ \\
Kereta Api & $2,1 \%$ & $0,1 \%$ & & & & & $1,1 \%$ \\
Laut & $2,7 \%$ & $0,2 \%$ & $58,8 \%$ & $3,6 \%$ & $0,2 \%$ & $79,7 \%$ & $24,2 \%$ \\
Jalan/Darat & $95,2 \%$ & $99,7 \%$ & $41,2 \%$ & $96,4 \%$ & $99,8 \%$ & $19,2 \%$ & $75,3 \%$ \\
\hline
\end{tabular}

Sumber: INDII (2014) 
Rasio ini menunjukkan masih minimnya kontribusi cargoterhadap pendapatan Garuda Indonesiayaitu masih dibawah $10 \%$ dari target $10-20 \%$ terhadap pendapatan perusahaan keseluruhan. Hal ini dikarenakan Garuda Indonesia baru fokus untuk mengembangakan unit bisnis ini dengan menjadikan divisi SBU Garuda Cargo sebagai direktorat sendiri, yaitu Direktorat Cargo pada awal tahun 2016 dan hingga saat ini masih dalam tahap pembenahan. Sebagai direktorat yang baru, tentunya dibutuhkan perubahan business model dari yang sebelumnya, serta membutuhkan strategi baru untuk dapat meningkatkan pendapatan sesuai dengan tujuan perusahaan.

Business model pengelolaan unit bisnis cargo yang ada saat ini dirasa belum mampu untuk menjawab tujuan perusahaan dan strategi yang ada sudah seharusnya dapat dikembangkan lebih baik lagi. Business model dan strategi yang akan dikembangkan harus sesuai dengan Visi dan Misi serta strategi jangka panjang perusahaan. Dalam menganalisis bisnis model dan rencana strategi bisnis, diperlukan juga analisis tingkat kepentingan dan kinerja dari elemen-elemen BMC serta analisis lingkungan industri persaingan yang sesuai dengan kondisi saat ini. Oleh karena itu, business model yang dikembangkan diharapkan dapat menjawab tujuan perusahaan yaitu mencapai pendapatan yang optimal serta berkontribusi lebih signifikan terhadap pendapatan PT. Garuda Indonesia, Tbk.

PenelitianmengenaiBMCsudahbanyakdilakukanantara lain oleh (Pujonggo, 2016; Thamrin, 2016). Perbedaan penelitian ini dengan sebelumnya adalah terletak pada studi kasus yaitu Direktorat Cargo PT. Garuda Indonesia, Tbk. Penelitian analisis BMC sebelumnya menggunakan analisis SWOT untuk membentuk BMC yang baru hal ini menjadikan penelitian kurang fokus terhadap elemen tertentu dikarenakan semua elemen ikut dianalisis dan akan menghasilkan strateginya masing-masing. Dalam membuat analisis BMC yang baru, peneliti melakukan pendekatan internal dengan alat analsis tingkat kepentingan dan tingkat kinerja (IPA) pada Sembilan elemen block BMC, untuk mendapatkan elemen prioritas yang harus dilakukan perubahan atau pengembangan. Penulis juga melakukan pendekatan eksternal dengan menganalisis persaingan industri mengguankan five forces porter serta melihat industri masa depan. Gabungan dari pendekatan internal dan eksternal inilah yang nanti menjadi dasar perubahan BMC dan menjadikan kebaruan serta membedakan dengan penelitian sebelumnya.
Penelitian ini bertujuan mengidentifikasi model bisnis Direktorat Cargo PT. Garuda Indonesia, Tbk menggunakan BMC, (2) membuat model bisnis baru Direktorat Cargo PT. Garuda Indonesia, Tbk menggunakan pendekatan BMC.

Model Bisnis adalah gambaran hubungan antara keunggulan dan sumber daya yang dimiliki perusahaan, serta kegiatan-kegiatan yang dilakukan untuk mengakuisisi dan menciptakan nilai, yang membuat perushaan mampu menghasilkan laba (PPM Manajemen, 2012). Menurut wheelen dan Hunger (2010) Model bisnis merupakan suatu metode untuk menghasilkan uang di lingkungan bisnis dimana perushaan tersebut beroperasi. Kajian dari (Zott et al. 2011) mengungkapkan bahwa model bisnis telah digunakan terutama dalam mencoba untuk mengatasi atau menjelaskan tiga fenomena: (1) e-business dan penggunaan teknologi informasi dalam organisasi; (2) isu strategis, seperti penciptaan nilai, keunggulan kompetitif, dan kinerja perusahaan; dan (3) inovasi dan manajemen teknologi.

Ruang lingkup pada penyusunan tesis ini difokuskan pada analisis bisnis model kanvas beserta faktorfaktor internal (kepentingan dan kinerja) dan eksternal (persaingan industri) Direktorat Cargo PT. Garuda Indonesia, Tbk, serta pembentukan bisnis model baru menggunakan $\mathrm{BMC}$ yang didasari oleh industri masa depan.

\section{METODE}

Penelitian ini dilakukan pada Direktorat Cargo PT. Garuda Indonesia, Tbk. selama bulan Maret sampai dengan Juni Tahun 2017. Penentuan responden pada penelitian ini dilakukan dengan purposive sampling, dengan pertimbangan responden yang dipilih memiliki kapasitas serta kemampuan dalam melihat kondisi lingkungan, kegiatan bisnis, dan menentukan strategi bisnis Cargo PT. Garuda Indonesia, Tbk. Menurut David (2013), dalam analisis ini untuk menentukan responden tidak ada jumlah minimal yang diperlukan, sepanjang responden yang dipilih merupakan ahli (expert) di bidangnya. Nair et al. (2011) mengidentifikasi metode yang tersedia untuk membandingkan model bisnis maskapai penerbangan dan meletakkan dasar bagi model kuantitatif untuk membandingkan model bisnis maskapai penerbangan. 
Data yang digunakan dalam penelitian ini merupakan data primer dan data sekunder. Data primer berupa data hasil FGD, serta wawancara mendalam (in-depth interview) dengan menggunakan bantuan kuesioner pada beberapa key informant yang meliputi 12 orang pejabat berwenang yang terdiri dari level Vice President hingga manager di Direktorat Cargo PT. Garuda Indonesia, Tbk. FGD dan kuisioner dilakukan untuk mengidentifikasi sembilan elemen BMC yang terjadi saat ini. Selain data primer yang diperoleh dari kuesioner, dibutuhkan juga data-data sekunder. Data sekunder menjadi data yang mendukung keberadaan data-data primer. Data sekunder berupa data PT. Garuda Indonesia yang diperoleh dari data laporan perusahaan dan data-data lain yang berhubungan dengan penelitian ini dan berasal dari berbagai sumber. Data yang diperoleh digunakan untuk menganalisis pendekatan internal maupun eksternal serta dianalisis menggunakan metode analisis deskriptif dan konsepkonsep manajemen strategis yang ada, sehingga mampu memberikan gambaran dan penjelasan mengenai masalah yang terjadi.

Penelitian ini dimulai dengan identifikasi model bisnis menggunakan BMC pada Direktorat Cargo PT. Garuda Indonesia, Tbk. Menurut Osterwalder dan Pigneur (2012), BMC dapat menyederhanakan model bisnis yang relative rumit menjadi lebih sederhana dengan menggunakan lembar kanvas tanpa mengurangi keakuratannya dalam mengidentifikasi, merumuskan, melaksanakan dan mengevaluasi suatu model bisnis dalam sebuah perusahaan atau organisasi. Kajian dari (Zott et al. 2011) mengungkapkan bahwa model bisnis telah digunakan terutama dalam mencoba untuk mengatasi atau menjelaskan tiga fenomena: (1) e-business dan penggunaan teknologi informasi dalam organisasi; (2) isu strategis, seperti penciptaan nilai, keunggulan kompetitif, dan kinerja perusahaan; dan (3) inovasi dan manajemen teknologi.

Strategi yang dirancang dalam penelitian ini diawali dengan menganalisis model bisnis Direktorat Cargo existing menggunakan BMC kemudian dianalisis dengan pendekatan internal dan eksternal. Pendekatan internal menggunakan IPA sehingga dapat menentukan prioritas blok mana yang harus di kembangkan. Pendekatan eksternal bertujuan menganalisis lingkungan persaingan industri dengan menggunakan analisis five forces porter serta dikaitkan dengan Industry foresight. Tahapan akhir dalam penelitian ini adalah menyusun New BMC Bisnis Cargo PT. Garuda Indonesia Tbk dengan pendekatan eksternal dan internal. Kerangka pemikiran penelitian selengkapnya pada Gambar 1.

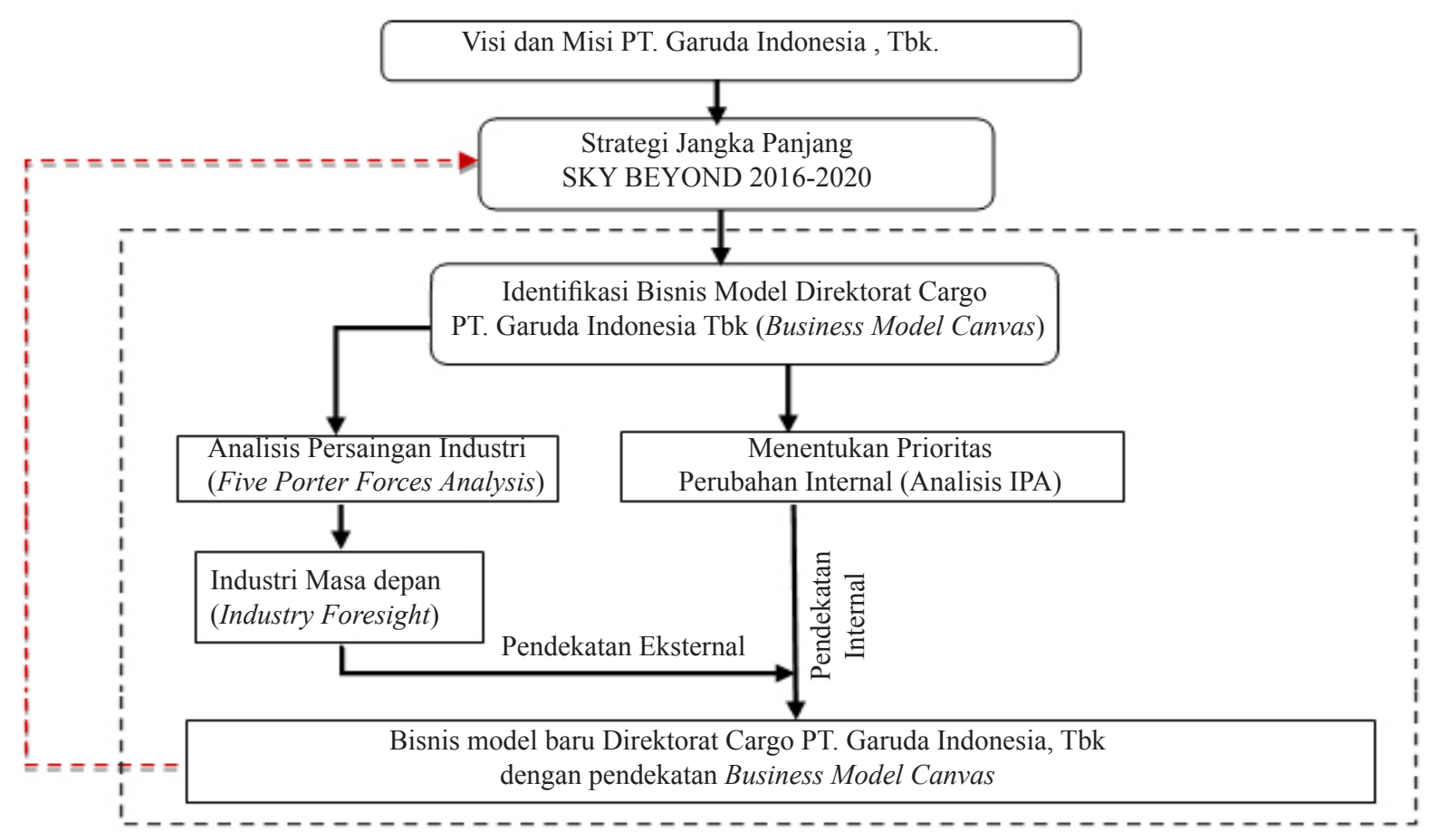

Gambar 1. Kerangka pemikiran penelitian 


\section{HASIL}

\section{Identifikasi Elemen Business Model Canvas Direktorat Cargo PT. Garuda Indonesia, Tbk}

Model bisnis menggambarkan dasar pemikiran bagaimana sebuah organisasi menciptakan, memberi, dan menangkap nilai (Nur et al. 2015). Penelitian ini dimulai dengan melihat bisnis Direktorat Cargo Garuda Indonesia, melalui identifikasi kesembilan elemen $\mathrm{BMC}$.

\section{Customer Segment}

Elemen ini ditargetkan kepada pelaku yang memiliki kebutuhan untuk pengiriman barang khususnya pengiriman barang yang memalui jalur udara. Adapun hasil yang didapat dari hasil FGD: Individu, Agen, dan Corporate yang membutuhkan pelayanan jasa pengiriman barang melalui udara untuk port to port/ city to city.

\section{Value Proposition}

Nilai yang diciptakan oleh Garuda Indonesia Cargo adalah Aman, Nyaman dan tepat waktu. Selain itu, Garuda Indoensia memiliki jaringan yang sangat luas hingga ke seluruh dunia. Meskipun tidak semua kota dan negara dapat diterbangi oleh Pesawat Garuda secara langsung. Saat ini Garuda Indonesia Cargo terbang ke 64 rute domestik dan 18 rute Internasional serta 60 rute kerja sama dengan maskapai lainnya.

\section{Channels}

Keegan (2005) menjelaskan bahwa saluran distribusi merupakan suatu struktur organisasi dalam perusahaan dan luar perusahaan yang terdiri dari agen, dealer, pedagang besar dan pengecer melalui sebuah komoditi, produk atau jasa yang ditawarkan. Berdasarkan FGD dan hasil wawancara dapat diketahui Garuda Indonesia hingga saat ini sudah memiliki dua saluran, yaitu direct channel dan Indirect channel.

\section{Customer Relationships}

Hubungan pelanggan yang saat ini dibangun oleh Garuda Indonesia antara lain Call Center, dimana fungsi tersebut terdapat pada Unit Cargo Customer Relationship Management (CRM). Unit Cargo CRM ini juga berperan sebagai Customer service yang memiliki tanggung jawab untuk menindaklanjuti klaim dan komplain dari para pelanggan Garuda Indonesia Cargo yang merasa dirugikan.

\section{Revenue Streams}

Garuda Indonesia Cargo merupakan bagian penting dari Garuda Indonesia karena meupakan salah satu revenue generator selain pendapatan dari penumpang. Pendapatan utama Garuda Indonesia Cargo sendiri saat ini tetap dari penjualan pengiriman cargo dan surat dokumen. Selain dari cargo dan surat dokumen, Garuda Indonesia Cargo juga memiliki arus pendapatan dari pengelolaan gudang di terminal cargo Bandara Soekarno Hatta, Cengkareng dan juga pendapatan lainnya dari biaya administrasi untuk Surat Muatan Udara (SMU).

\section{Key Resources}

Bisnis Garuda Indonesia Cargo akan berjalan dengan lancar jika sumber daya utama dan pendukung juga berjalan dengan baik. Sumber daya manusia merupakan salah satu sumber daya utama yang dimiliki oleh Garuda Indonesia Cargo. Pencapaian tujuan suatu perusahaan sangat bergantung pada kualitas sumber daya manusia (Sarinah et al. 2016), dimana saat ini jumlah karyawan mencapai 308 orang serta ribuan tenaga outsourcing yang juga ikut membantu kelancaran bisnis proses Garuda Indonesia Cargo diseluruh dunia. Selain itu, sebagai maskapai tentunya ketersediaan belly space pada pesawat merupakan sumber daya utama dan hal penting karena merupakan alat produksi Garuda Indonesia Cargo. Saat ini Garuda Indonesia Cargo juga memiliki Kantor CSC sebanyak 80 kantor di seluruh Indonesia yang mana 64 kantor merupakan milik sendiri, dan 16 kantor merupakan kantor kerja sama operasi (KSO).

\section{Key Activities}

Kegiatan pada Garuda Indonesia Cargo saat ini terbagi menjadidua, yaituaktivitas commercial danoperational. Kegiatan ini melayani pengiriman barang melalui udara untuk layanan port to port, dan city to city. Commercial Activities meliputi Sales Activtiy, promotion activity, after sales activity. Selanjutnya, Operational Activities meliputi Warehouse management, Cargo Handling. 


\section{Key Partnership}

Bisnis proses Garuda Indonesia Cargo tidak akan dapat berjalan sendiri jika tidak bermitra dengan pihak ketiga lainnya baik untuk dari sisi commercial, operational serta business support. Tujuannyatidak lain adalah untuk memastikan bisnis proses berjalan lancar, mengurangi risiko, atau memperoleh sumberdaya. Kemitraan utama yang dilakukan oleh Garuda Indonesia Cargo dari sisi commercial antara lain dengan agen, CSC KSO, corporate. Dari sisi operational, Garuda Indonesia Cargo bekerjasama dengan Gapura Angkasa, Angkasa Pura I dan II, Regulated Agent, Kementerian Perhubungan serta Bea Cukai. Dari sisi business support Garuda Indonesia Cargo sudah bekerjasama dengan Mercator dan Cargo Flash terkait system, persale terkait penyedia SDM, dan garuda karya mandiri terkait manajemen building.

\section{Cost Structure}

Struktur Biaya yang ada pada Garuda Indonesia Cargo terdiri dari, Biaya overhead, biaya sumberdaya manusia, dan belly space rate. Biaya overhead terdiri dari biaya sewa gedung kantor, biaya operasional gedung kantor, serta biaya yang ditimbulkan untuk memenuhi kebutuhan sales dan operasional. Sedangkan untuk belly space rate adalah perhitungan biaya yang harus dikeluarkan.

\section{Gambaran Existing Business Model Canvas}

Hasil pengamatan, pengisian kuesioner, wawancara, dan FGD yang dilakukan maka diperoleh gambaran pada setiap blok elemen BMC Direktorat Cargo (existing). Adapun hasil identifikasi ini dapat dilihat pada Gambar 2.

\section{Model Bisinis Perbaikan BMC Direktorat Cargo PT. Garuda Indonesia, Tbk}

Perbaikan BMC diawali dengan pendekatan internal yaitu menganalisis tingkat kepentingan dan kinerja dari masing-masing elemen BMC yang telah teridentifikasi. Analisis Pendekatan eksternal dengan Five porter dan industry foresight juga akan memberikan masukan terhadap perbaikan BMC yang baru.



Gambar 2. Identifikasi existing BMC Direktorat Cargo 


\section{Pendekatan Internal}

Analisis IPA BMC Direktorat Cargo PT. Garuda Indonesia, Tbk

Importance-Perfomance Analysis (IPA) adalah suatu teknik yang digunakan untuk mengukur atribut-atribut atau dimensi-dimensi dari tingkat kepentingan dan kinerja yang diharapkan konsumen dan sangat berguna bagi pengembangan program strategi perusahaan yang efektif (Simamora, 2004). Babu (2015) menggunakan analisis IPA untuk menentukan daftar prioritas yang akan diperbaiki pada item pelayanan bandara. BMC yang sudah teridentifikasi maka langkah berikutnya adalah melakukan analisis tingkat kinerja dan tingkat kepentingan terhadap sembilan blok elemen tersebut. IPA digunakan untuk menilai kepentingan dan kinerja. Hasil Analisis IPA pada Gambar 3.

Analisis IPA pada Sembilan elemen block BMC Direktorat Cargo menghasilkan bahwa terdapat tiga elemen penting masuk kedalam Kuadran I sehingga diperlukan melakukan perubahan atau pengembangan. Elemen yang terdapat pada Kuadran I (prioritas utama) antara lain customer segment, revenue stream, dan channels.

\section{Pendekatan Eksternal}

\section{Analisis Industri Five Forces Porter}

Analisis Five forces Porter bertujuan mengetahui lingkungan Industri cargo dan Garuda Indonesia Cargo merupakan salah satu pelaku didalamnya. Turkish Airline dalam (Acar dan Karabulak, 2015) telah menciptakan strategi yang berbeda dalam lingkungan yang kompetitif ini, telah mencoba untuk memposisikan diri dalam hal strategi kompetitif Porter dan, berdasarkan konsep strategi, mereka sudah mulai menggunakan alat strategis baru. Analisis five forces porter menggambarkan bahwa tingkat intesitas persaingan antar pemain yang ada saat ini (competitor) cukup tinggi, kemudian untuk tingkat anacaman masuknya pendatang baru (new entrants) juga masih rendah, kekuatan tawar menawar pemasok (bargaining power of Suppliers) berada pada tingkat sedang, kekuatan tawar pembeli (bargaining power of Buyer) memiliki tingkat yang tinggi dikarenakan jumlah pembeli semakin banyak serta informasi yang diperoleh dapat membuat pembeli melakukan penawaran. Ancamam produk pengganti (substitute product) juga cukup tinggi.

\section{Industry Foresight}

Setiap industri mengalami proses perkembangan (Supratikno, 2005). Menurut Hamel dan Prahalad (1995), masa depan adalah persaingan untuk memaksimalkan bagian dari peluang yang secara potensial dapat diraih oleh perusahaan dalam suatu arena persaingan yang luas. Strategi adalah pemikiran bisnis futuristik tentang tantangan bisnis saat ini dan peluang masa depan (Betz, 2002). Sektor jasa pengiriman barang ini juga tidak terlepas dari majunya industri lainnya. Industri ecommerce yang dimasa depan akan sangat pesat tentunya juga membutuhkan layanan pengiriman barang dari tempat produksi hingga ke konsumen. Perkembangan Teknologi Informasi (TI) dewasa ini tumbuh sangat pesat sehingga memberikan dampak perubahan besar dalam segala bidang (Pamungkas, 2016) termasuk industri cargo udara.

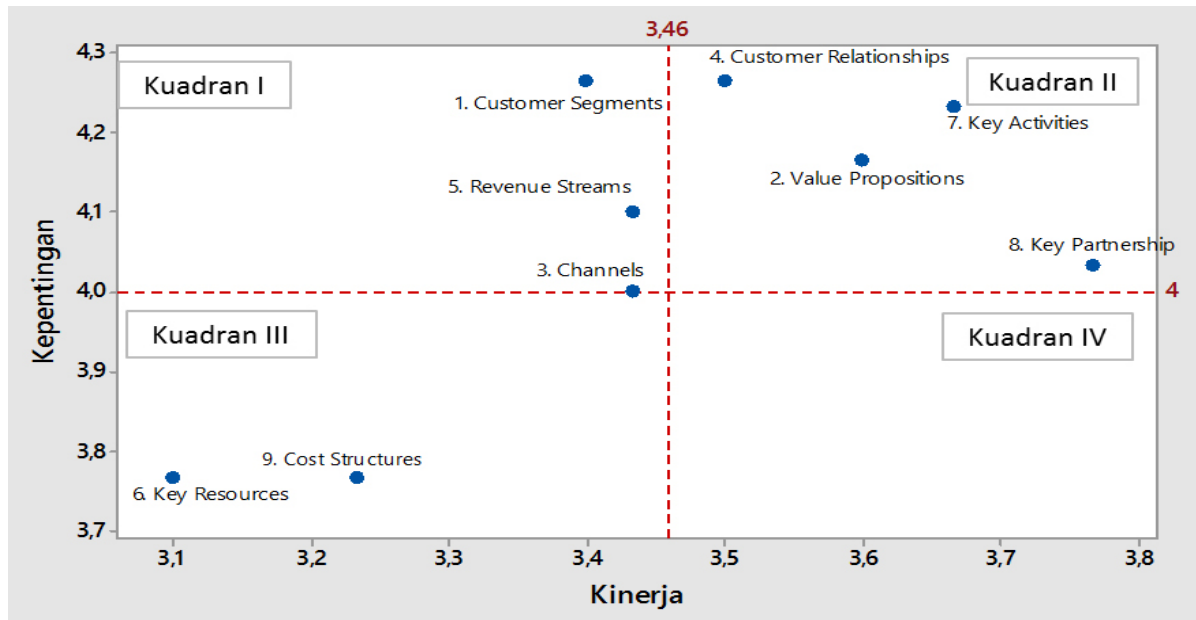

Gambar 3. Kuadran tingkat kepentingan vs kinerja sembilan elemen BMC Direktorat Cargo 
Saat ini berdasarkan data dari INACA, Industri Cargo Udara di Indonesia masih tumbuh sekitar 3,5 persen sepanjang 2016 dan hal ini terlihat positif jika dibandingkan tahun 2015 yang tumbuh di angka 1,75 persen. Namun, dibandingkan dengan pertumbuhan industri e-commerce sebesar $40 \%$ maka hal ini tentunya menjadi gap yang sangat besar. Pada masa yang akan datang, bertumbuhnya indutri e-commerce yang pesat juga tentu akan mendorong peningkatan pertumbuhan industri Cargo udara.

\section{Perbaikan BMC Direktorat Cargo PT. Garuda Indonesia, Tbk}

Hasil analisis IPA didapat ada beberapa elemen dimana tingkat kepentingannya tinggi namun kinerja elemen tersebut masih rendah, maka dibutuhkan perbaikan business Model Canvas Direktorat Cargo. Analisis IPA menunjukkan terdapat 3 elemen BMC yang sebaiknya dirubah atau dikembangkan, yaitu elemen Customer Segment, elemen Revenue Streams, dan elemen Channels. Analisis Five porter menjadi masukkan terhadap perubahan ataupengembangan BMCyangakan dilakukan. Perbaikan BMC berdasarkan analisis IPAdan masukan dari analisis Five porter akan menghasilkan BMC Baru dimana dapat menjadi masukan kepada Direktorat Cargo dalam mengembangkan bisnisnya kedepan.

\section{Perbaikan elemen Customer Segment}

Pada hasil FGD dan wawancara bahwa Customer tersebut dirasa kinerja nya belum baik dan dibutuhkan perbaikan yang sifatnnya pengembangan. Adanya perkembangan industri Cargo udara selalu dihubungkan dengan adanya peningkatan industri e-commerce maka untuk Customer segment juga agar dikembangkan untuk menangkap peluang tersebut. Berdasarkan hal tersebut Customer segment Garuda Indonesia Cargo dapat dikembangkan menjadi: B2C (Individu yang membutuhkan pelayanan jasa pengiriman barang untuk pelayanan port to port / city to city/door to door) dan B2B (Perusahaan/BUMN/Kementerian/lembaga/ Carrier/Agen/subagen/kurir/e-commerce/LSP yang membutuhkan pelayanan jasa pengiriman barang untuk pelayanan port to port/city to city/door to door).

Penambahan Customer ecommerce serta perluasan layanan tidak hanya melalui udara namun juga dapat melalui seluruh transportasi baik udara, darat dan laut. Pengembangan ini nantinya akan berdampak pada elemen-elemen lainnya serperti perluasan channel, pengembangan kerjasama partnership, serta peningkatan revenue.

\section{Perbaikan elemen Channel}

Saat ini channel Garuda Indonesia Cargo masih didominasi oleh Indirect Channel, yaitu agent yang mana berkontribusi sekitar $89 \%$ terhadap total revenue. Kondisi ini dipandang oleh manajemen merupakan hal yang kurang baik sehingga dianggap kinerja channel masih perlu dirubah dan dikembangkan. Proporsi Direct channel pada tahu 2017 ditargetkan menjadi 15\% sehingga proposi Indirect channel harus ditargetkan turun menjadi $85 \%$. Oleh karena itu channel pada Indirect harus diperbanyak. Berdasarkan keterangan diatas pengembangan channel distribuition pada Garuda Indoneisa dapat dilakukan dengan mengembankan turunan dari CSC seperti Gerai dan Sales Outlet. Outlet dapat dikerjasamakan dengan BUMN yang memiliki jaringan yang kuat serta merupakan bentuk Sinergi BUMN. POS Indonesia, KA Logistik, Pelni, Angkasa Pura, Pertamina. Selain Outlet juga dapat dibuat gerai atau small counter yang nantinya mudah diakses oleh konsumen akhir.

\section{Perbaikan elemen Revenue Streams}

Berdasarkan analisis IPA kinerja dari elemen Revenue Stream masih dibawah rata-rata sehingga menujukan perlu adanya pengembangan agar dapat meningkatkan pendapatan bagi Garuda Indonesia Cargo. Pengembangan yang dilakukan pada elemen Customer Segmen dan Channel mendorong untuk adanya perbaikan pada revenue streams. Input dari Industry foresight dimana adanya peningkatan demand dikarenakan akan berkembangnya industri ecommerce kedepan, maka pengembangan dari elemen revenue streams dapat ditambahkan dengan pendapatan dari trucking door to door, pendapatan dari fee based income serta sharing pendapatan dari sinergi BUMN.

\section{Perbaikan elemen Customer Relations}

Pada BMC yang baru ditambahkan mengenai komunikasi dengan pelanggan tidak hanya melalui telepon saja. Namun, komunikasi harus terbuka dan dapat disampaikan melalui website, email, whatsapp, ataupun system Customer service online. Hal ini juga harus didukung oleh SOP mengenai CRM bagaimana cara menjawab atau menanggapi, berapa lama harus 
ditanggapi dan berapa lama msalah diselesaikan. Selain komunikasi, pelanggan juga akan tertarik dan menjadi loyal dengan loyalty program. Garuda Indoneisa sudah terkenal dengan Garuda Miles-nya dan hal ini bisa menjadi daya tarik jika juga diterapkan pada customer Garuda Indonesia Cargo. Dengan menerapkan loyalty program ini tentunya juga akan dapat dikerjsamakan dengan loyalty program yang dimiliki oleh intansi BUMN ataupun e-commerce sehingga akan lebih menarik. Khusus pelanggan agent, untuk mempererat hubungan makan juga dapat dibuat agent gathering serta kunjungan rutin dan pemberian hadiah yang dapat berupa FoC tiket pesawat atau birthday cake untuk owner/key person dari agent.

\section{Perbaikan elemen Value Proposition}

Identifikasi pada kondisi existing blok elemen value proposition menunjukkan bahwa Garuda Indonesia Cargo memiliki value antara lain kecepatan dan ketepatan waktu dalam pengiriman barang port to port serta memiliki jangkauan yang luas. Meskipun demikian, pada analisis IPA elemen ini termasuk dalam kuadran yang harus dipertahankan namun dikarenakan adanya pengembangan pada elemen prioritas maka Value ini juga perlu dikembangkan. Berkembangnya Customer segment ke arah door to door serta merambah ke pasar retail dan e-commerce maka Value proposition yang dapat ditambahkan menjadi seperti berikut: priority dan guaranteed delivery; one stop service dan payment; competitive price; door to door dan city to door service; easy tracking dan tracing.

\section{Perbaikan elemen Key Activities}

Kegiatan Utama Garuda Indonesia Cargo pada identifikasi awal terdiri atas kegiatan operational dan commercial. Kegiatan commercial selain kegiatan penjualan, juga termsauk kegiatan pemasaran, perubahan terjadi adalah kegiatan pengiriman barang yang awalnya hanya melayanai port to port dan city to city, kegaiatan melayani layanan door to door. Hal ini merupakan penyesuaian dari hasil perubahan pada elemen customer segment. Untuk kegiatan operasional, yaitu pengelolaan gudang khususnya di Terminal Cargo Bandara Soekarno Hatta. Pengembangan untuk kegiatan Utama ini tidak terlau banyak hanya lebih untuk memastikan kegiatan tersebut berjalan dengan baik dan tepat sehingga dibutuhkan SOP untuk segala business proses yang ada.

\section{Perbaikan elemen Key Patnership}

Elemen key patnership pada identifikasi awal dapat dilihat dari tiga sisi, yaitu commercial, operational dan business support. Berdasarkan analisis IPA Key partnership memiliki tingkat kinerja yang paling tinggi dan masuk dalam Kuadran II. Meskipun begitu, berada pada Kuadran II elemen ini tetap akan mengalami perubahan dengan penambahan beberapa patner dikarenakan adanya perubahan pada customer segment dan channel serta dalam rangka memepersiapkan persaingan dimasa depan. Sisi commercial Garuda Indonesia Cargo sudah melakukan partnership dengan Agen, CSC KSO, corporate, dan akan mengembangkan kerjssama dengan asosiasi logistic, asosiasi UKM/ Koperasi, sinergi BUMN, kementerian/lembaga, dan anak perusahaan aero express. Dari sisi operational, Garuda Indonesia Cargo sudah bekerja sama dengan gapura angkasa,angkasa pura I dan II, regulated agent, kemenhub, serta bea cukai. Dari sisi business support Garuda Indonesia juga melakukan kerjasama dengan Mercator dan Cargo Flash terkait system, persale terkait penyedia SDM, garuda karya mandiri terkait manajemen building serta media nasional.

\section{Perbaikan elemen Key Resources}

Hasil analisis IPA, blok elemen ini termasuk yang memiliki tingak kepentingan dan kinerja rendah, maka dibutuhkan perbaikan agar kinerja nya meningkat sehingga dapat mendukung elemen lainnya. Perbaikan yang perlu dilakukan adalah melakukan pengembangan SDM yang ada saat ini dengan mengikuti trainingtraning yang berstandar internasional serta tersertifikasi dengan baik, sehingga bermanfaat bagi Garuda Indonesia Cargo. Selain itu asset yang dimiliki baik kantor CSC hingga aircraft harus benar-benar efisien digunakan sehingga tidak memberi beban pada perusahaan dalam perawatannya.

\section{Perbaikan elemen Cost Structure}

Identifikasi pada kondisi existing blok elemen cost structure menunjukan bahwa biaya yang terdapat pada Direktorat Cargo terdiri dari biaya sales and promotion, operational, overhead, fuel cost, belly space rate dan Biaya Sumber daya Manusia. Untuk perubahan pada business model yang baru tidak ada penambahan biaya komponen namun yang akan ditekankan adalah mengenai cost efisiensi pada elemen ini dikarenakan 
profit sebuah perusahaan sangat terkait dengan biaya yang dikeluarkan. Perbaikan dari tiga elemen prioritas menjadi dasar pada perbaikan elemen lainnya. Hal ini dapat dilihat pada Gambar 4.

Berkembangnya elemen Customer segment mampu memengaruhi element lainnya antara lain Value Preposition, Key Activities dan Key Patners. Value Preposition dan Key Activties menampilkan layanan door to door yang akan ditawarkan. Key Patners juga bertambah sesuai pengembangan Customer segment. Pengembangan elemen lainnya bertujuan menyesuaikan pengembangan elemen prioritas. Pengembangan ini juga suda menadapat masukan dari pendekatan internal dan eksternal.

\section{Implikasi Manajerial}

Implikasi manajerial yang terkait penelitian ini berfokus pada tiga elemen yang menjadi prioritas untuk diperbaiki atau dikembangkan. Implikasi pada customer segment, perusahaan dapat merubah strategi dan program kerja yang awalnya berfokus ke B2B menjadi fokus ke B2C. Strategi dan program kerja yang dibuat harus mengarah ke B2C dan juga menyasar segmen yang membutuhkan layanan door to door. Program kerja Garuda Indonesia Cargo dapat menjadi lebih besar nantinya karena pasar yang di target semakin luas namun tetap mengedepankan efisiensi dan efektivitas. Program promosi misalnya sudah seharusnya menggunakan program yang mengarah ke digitalisasi bukan lagi seperti penyebaran flyer, leaflet dan sebagainya. Kombinasi promosi dengan metode ATL (above the line) dan BTL (below the line) dapat digunakan untuk menyasar konsumen yang luas namun mengedepankan efisiensi, promosi di media sosial misalnya merupakan salah satu cara agar perusahaan dapat melakukan efisiensi program.

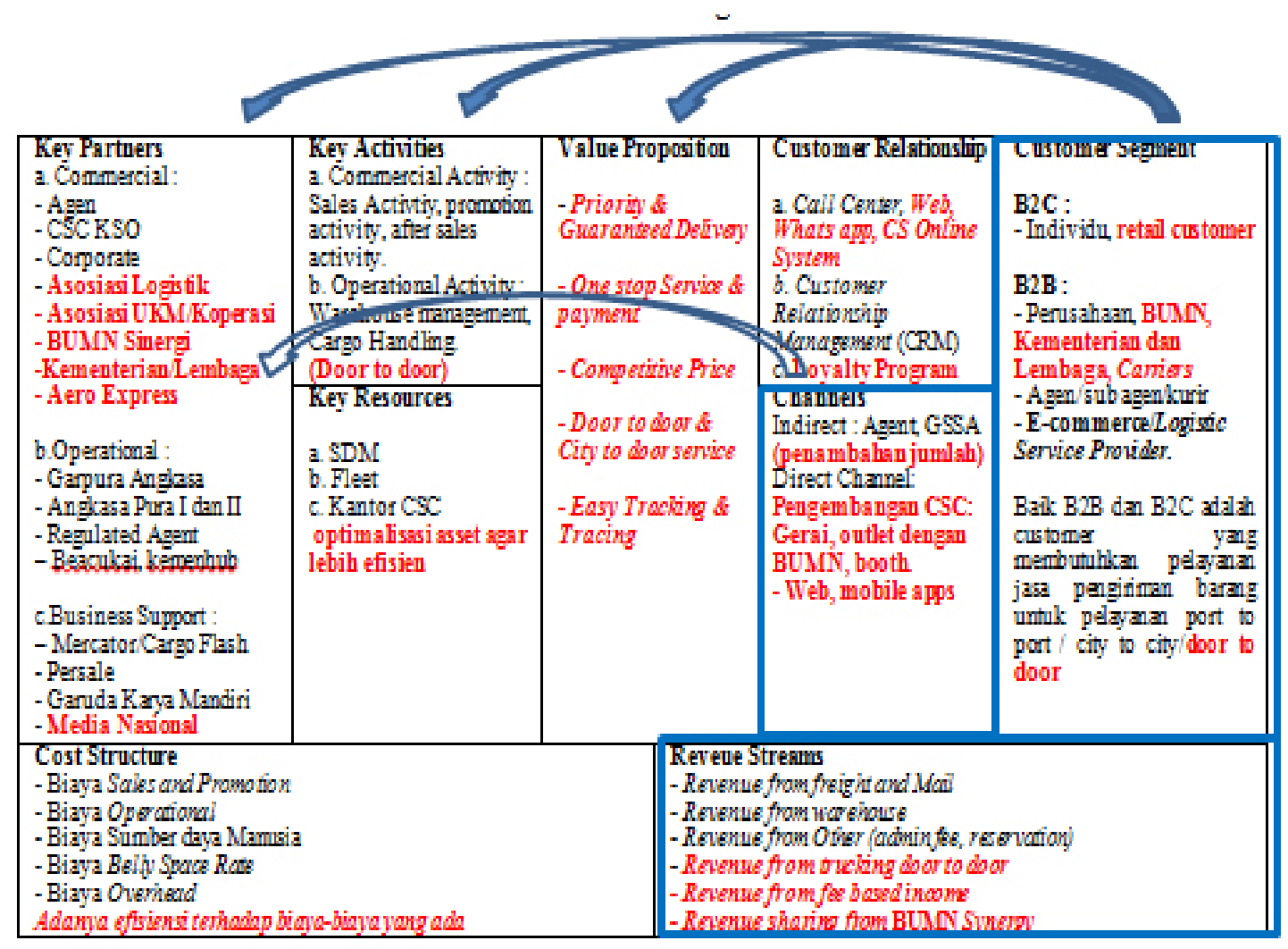

Gambar 4. Perbaikan dari tiga elemen prioritas menjadi dasar pada perbaikan elemen lainnya 


\section{KESIMPULAN DAN SARAN}

\section{Kesimpulan}

Identifikasi Business Model Canvas (BMC) Direktorat Cargo berhasil dilakukan yang terdiri atas sembilan elemen blok, yaitu customer segment, Value preposition, channels, customer relationship, revenue streams, key resources, key activities, key patnership dan cost structure. Hasil dari identifkasi BMC, analisis tingkat kepentingan dan tingkat kinerja serta masukan dari analisis five forces porter dan industry foresight maka terbentuklah New BMC Direktorat cargo yang menitik beratkan pada tiga elemen yaitu pada customer segment, channels dan revenue stream. Element customer segment dibagi menjadi B2C dan B2B serta adanya pengembangan service Door to door. Pada elemen channel terjadi pengembangan CSC menjadi gerai, outlet serta penambahan jumlah di seluruh channel. Revenue streams terjadi penambahan pendapatan dari fee based income, trucking door to door, serta revenue sharing dari kerjasama dengan pihak ketiga. Perubahan elemen diatas serta adanya masukan dari analisis industri juga mengakibatkan perubahan pada blok elemen lainnya. Perubahan pada New BMC ini nantinya akan menjadi dasar Direktorat Cargo untuk membuat strategi dan program kerja dalam rangka peningkatan kinerja.

\section{Saran}

Direktorat Cargo meningkatkan kinerja dengan merubah business model yang ada saat ini dengan New BMC yang merupakan hasil dari penelitian ini. Garuda Indonesia Cargo agar dapat fokus kepada 3 elemen, yatiu customer segment, channel dan revenue streams. Adanya perubahan pada business model dapat berfungsi sebagai dasar untuk menciptakan strategi direktorat untuk dapat meningkatan performance kinerja sehingga profit margin menngkat dan memenangkan persaingan. Penelitian selanjutnya perlu melakukan penelitian yang terkait dengan bagaimana strategi Direktorat Cargo kedepan dengan dasar hasil penelitian ini, yaitu perubahan BMC. Strategi ersebut juga tidak lupa harus melihat industry foresight serta faktor-faktor yang memengaruhi industri cargo udara, sehingga nantinya Direktorat cargo akan memiliki strategi yang dapat berguna sebagai alat untuk meningkatkan kinerja perusahaan dan memenangkan persaingan

\section{DAFTAR PUSTAKA}

Acar AZ, Karabulak S. 2015. Competition between full service network carriers and low cost carriers in Turkish Airline market. Procedia - Social and Behavioral Sciences 207: 642-651. https://doi. org/10.1016/j.sbspro.2015.10.134.

Babu, JA. 2015. Airport service improvement strategies using importance-performance analysis. International Journal for Research in Applied Science dan Engineering Technology 3(5): 381392.

Betz F. 2002. Strategic business models. Engineering Management Journal 14(1): 21-27. https://doi.o $\mathrm{rg} / 10.1080 / 10429247.2002 .11415145$.

David FR. 2014. Strategic Management: Concepts and Cases. 15th Ed. New Jersey: Pearson Education Inc-Preentice Hall.

Hamel, G dan Prahalad, C.K. 1994. Kompetisi Masa Depan (Terjemahan). Boston: Havard Business School Press.

Keegan WJ. 2005. Manajemen Pemasaran Global (terjemahan). Ed ke -6. Jakarta: PT Indeks Kelompok Gramedia.

Martila JA, James JC. 1977. Importance-performance analysis. Journal of Marketing 41: 77-79. https:// doi.org/10.2307/1250495.

Nair SK, Palacious M, Ruiz F. 2011. The analysis of airline business models in the development of possible future business options. World Journal of Management 3(1): 48-59.

Nur AA, Nur FAB, Farah NH, Jamaludin. 2015. Comparison of BMC among the three consulting companies. International Journal of Computer Science and Information Technology Research 3(2): 462-471.

Osterwalder A, Pigneur Y. 2012. Business Model Generation. Jakarta: Elex Media Komputindo.

Pamungkas DP. 2016. Analisis competitive force dan competitive strategy sistem informasi kuliner di Indonesia (Studi Kasus: Kulina.id). Jurnal Electronics, Informatics, and Vocational Education 1(2): 118-127.

PPM Manajemen. 2012. Business Model Canvas, Penerapan di Indonesia. Jakarta: Penerbit PPM.

Porter ME. 2008. The Five Competitive Forces That Shape Strategy. Havard Business Review. January 2008.

Pujonggo RY. 2016. Arsitektur Strategi inspektorat jenderal kementrian perdagangan Republik Indonesia [tesis]. Bogor: Institut Pertanian 
Bogor.

Richard B, Stefan S. 2014. Analysis of business models. Journal od Competitiveness 6(4):19-40. https:// doi.org/10.7441/joc.2014.04.02.

Ropi F, Fahmi I, Suprayitno G. 2017. Factors influence satisfaction and loyalty towards corporate Patner Program Garuda Indonesia. International Journal of Scientific and Research Publications 7(2):194-205.

Setiani B. 2015. Prinsip-prinsip pokok pengelolaan jasa transportasi udara. Jurnal Ilmiah WDYA 3(2):103-109.
Simamora B. 2004. Panduan Riset Perilaku konsumen. Jakarta: PT. Gramedia Pustaka Utama.

Supratikno H. 2005. Advanced Strategic Management: Back to Basic Approach. Jakarta: PT. Gramedia Pustaka Utama.

Thamrin I. 2016. Strategi pengembangan bisnis kemitraan minuman teh siap saji YourTea dengan pendekatan model bisnis kanvas [tesis]. Bogor: Institut Pertanian Bogor.

Zott C, Amir R, Masa L. 2011. The business model: recent developments and future research. Journal of Management 37(4): 1019-1042. https://doi. org/10.1177/0149206311406265. 